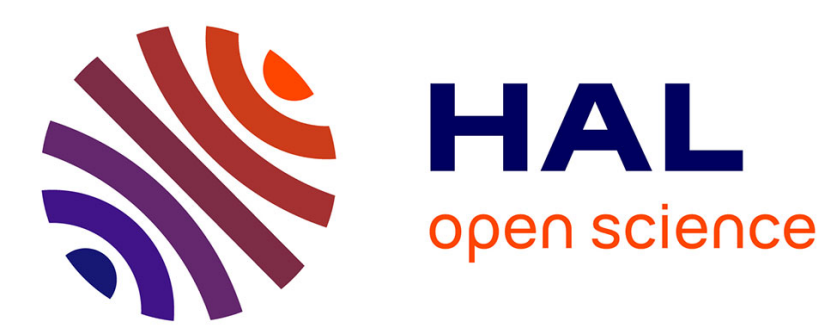

\title{
Oxytocin Signaling in Pain: Cellular, Circuit, System, and Behavioral Levels
}

Pierrick Poisbeau, Valery Grinevich, Alexandre Charlet

\section{To cite this version:}

Pierrick Poisbeau, Valery Grinevich, Alexandre Charlet. Oxytocin Signaling in Pain: Cellular, Circuit, System, and Behavioral Levels. Behavioral Pharmacology of Neuropeptides: Oxytocin, pp.193-211, 2017, 10.1007/7854_2017_14. hal-02166023

\section{HAL Id: hal-02166023 \\ https://hal.science/hal-02166023}

Submitted on 4 Nov 2020

HAL is a multi-disciplinary open access archive for the deposit and dissemination of scientific research documents, whether they are published or not. The documents may come from teaching and research institutions in France or abroad, or from public or private research centers.
L'archive ouverte pluridisciplinaire HAL, est destinée au dépôt et à la diffusion de documents scientifiques de niveau recherche, publiés ou non, émanant des établissements d'enseignement et de recherche français ou étrangers, des laboratoires publics ou privés. 


\title{
Oxytocin Signaling in Pain: Cellular, Circuit, System, and Behavioral Levels
}

\author{
Pierrick Poisbeau, Valery Grinevich, and Alexandre Charlet
}

\begin{abstract}
Originally confined to the initiation of parturition and milk ejection after birth, the hypothalamic nonapeptide oxytocin (OT) is now recognized as a critical determinant of social behavior and emotional processing. It accounts for the modulation of sensory processing and pain perception as OT displays a potent analgesic effect mediated by OT receptors (OTRs) expressed in the peripheral and central nervous systems. In our chapter, we will first systemically analyze known efferent and afferent OT neuron projections, which form the anatomical basis for OT modulation of somatosensory and pain processing. Next, we will focus on the synergy of distinct types of OT neurons (e.g., magno- and parvocellular OT neurons) which efficiently control acute inflammatory pain perception. Finally, we will describe how OT signaling mechanisms in the spinal cord control nociception, as well as how OT is able to modulate emotional pain processing within the central amygdala. In the conclusions at the end of the chapter, we will formulate perspectives in the study of OT effects on pain anticipation and pain memory,
\end{abstract}

Pierrick Poisbeau, Valery Grinevich and Alexandre Charlet contributed equally to this work.

P. Poisbeau

Centre National de la Recherche Scientifique, University of Strasbourg, Institut des

Neurosciences Cellulaires et Intégratives, Strasbourg, France

V. Grinevich

Schaller Research Group on Neuropeptides, German Cancer Research Center, Heidelberg, Germany

Central Institute of Mental Health, Mannheim, Germany

A. Charlet $(\triangle)$

Centre National de la Recherche Scientifique, University of Strasbourg, Institut des

Neurosciences Cellulaires et Intégratives, Strasbourg, France

University of Strasbourg Institute for Advanced Study, USIAS, Strasbourg, France

e-mail: acharlet@unistra.fr 
as well as propose some reasons for the application of exogenous OT for the treatment of certain types of pain in human patients.

Keywords Amygdala • Hypothalamus • Nociception • Oxytocin • Oxytocin receptor $\bullet$ Pain $\cdot$ Spinal cord

\section{Contents}

1 Introduction

2 Physiological and Behavioral Evidence

3 OT Neurons Involved in the Modulation of Pain

3.1 Magnocellular OT Neurons

3.2 Parvocellular OT Neurons

3.3 Circuits for Pain-Induced Activation of OT Neurons

4 Supraspinal Structures Involved in Oxytocinergic Modulation of Pain

4.1 Cortex

4.2 Central Amygdala

4.3 PAG

4.4 Raphe Nuclei

4.5 Nucleus Accumbens

5 Spinal Structures Involved in Oxytocinergic Modulation of Nociception

5.1 Oxytocinergic Modulation of Spinal Network

5.2 Mechanisms for Spinal Antinociception

6 Conclusion

References

\section{Introduction}

Since the synthesis of oxytocin (OT) by the groups of Vincent du Vigneaud (du Vigneaud 1954-1955) and Roger Acher (Acher and Fromageot 1955), OT has been classically described as a neurohormone, synthesized exclusively in the hypothalamic nuclei. OT binds to a single type of OTR (Kimura et al. 1992), expressed by myometrial cells of the uterine and myoepithelial cells of the mammary gland. Muscle contraction is then ensured by an intracellular $\mathrm{Ca}^{2+}$ increase, triggered by the local production of inositol trisphosphate thanks to a $\mathrm{G}_{\mathrm{q}}$ protein coupling to phospholipase $\mathrm{C}$.

In addition to its neurohormonal action on peripheral targets, OT acts as a neuromodulator in the central nervous system (CNS) and modulates a large number of brain functions, including social behaviors, emotions, and pain (Lee et al. 2009; see also Bosch and Young 2017). Despite the diverse behavioral effects of OT, we only start to understand the complexity of OTR-mediated intra-neuronal signaling (see Busnelli and Chini 2017). OTR are G-protein-coupled receptors which are capable of either increasing (Knobloch et al. 2012; Stoop 2012) or inhibiting (Eliava et al. 2016) neuronal excitability due to different mechanisms. One of these mechanisms is the dual OTR coupling to $\mathrm{G}_{\mathrm{q}}$ or $\mathrm{G}_{\mathrm{o}} / \mathrm{G}_{\mathrm{i}}$ proteins (Gravati et al. 2010; Busnelli et al. 2012). 
However, little is known about the intracellular OTR effectors and signaling pathways downstream of $\mathrm{G}$ protein activation and, in particular, about the effectors known to be relevant to neuronal cells and brain functions. One of the most important intracellular signaling pathways activated by OTRs is the mitogen-activated protein kinase (MAPK) cascade. Inga Neumann's team has demonstrated that OTR/MEK/ ERK signaling mediates OT anxiolytic effects (Blume et al. 2008; Jurek et al. 2012; van den Burg et al. 2015), which requires the influx of extracellular calcium through transient receptor potential vanilloid (TRPV) channels. In particular, OTR activation in hypothalamic neurons induces the release of $\mathrm{G}_{\mathrm{bg}}$ and PI3K activation, thus promoting the incorporation of TRPV channels in the plasma membrane and consequent calcium influx and MEK 1/2 phosphorylation (van den Burg et al. 2015). It is likely that $\mathrm{Ca}^{2+}$-activated calmodulin-dependent activation of the EGFR is involved in this process, but the cascade of the molecular players involved is still unknown (Blume et al. 2008). It is interesting to note that OTR activation has also been associated with the stimulation of ERK $1 / 2$ activity in the superficial layers of the spinal cord, as well as the local increased production of analgesic neurosteroids (Juif et al. 2013). It is expected that OTRs activate other signaling pathways in neuronal (and glial) cells and progress in this area will certainly contribute to further advances in OT studies.

In particular, it would not be surprising to observe particular signaling cascades as a function of the brain-region function, including those involved in pain processing. Indeed, OT axonal projection and OTR expression were shown in several structures known to process the different components of "pain messages," such as the superficial layers of spinal cord, the medial amygdala, the periaqueductal gray matter, or the ventral tegmental area (Fig. 1).

As illustrated in Fig. 1, pain processing involves a large number of CNS structures and gives rise to an unpleasant emotion which can be defined as "an adaptive aversive experience with sensory, emotional, cognitive, and social components" (Williams and Craig 2016). To become a conscious sensation, nociceptive messages reach the cortical areas using various ascending tracts (spinothalamic, spinoreticular, and spino-parabrachio-amygdaloid tracts). Meanwhile, collaterals are sent to intermediate structures in the brainstem (rostroventral medulla and periaqueductal gray), the limbic system (amygdala), and the diencephalon (hypothalamus and thalamus). Processing of nociceptive messages by these structures is accompanied by the parallel recruitment of descending pain controls located in some cortical areas, hypothalamus, amygdala, and the brainstem. OT neurons are involved in this active process at hierarchically different levels, described in the section below. 


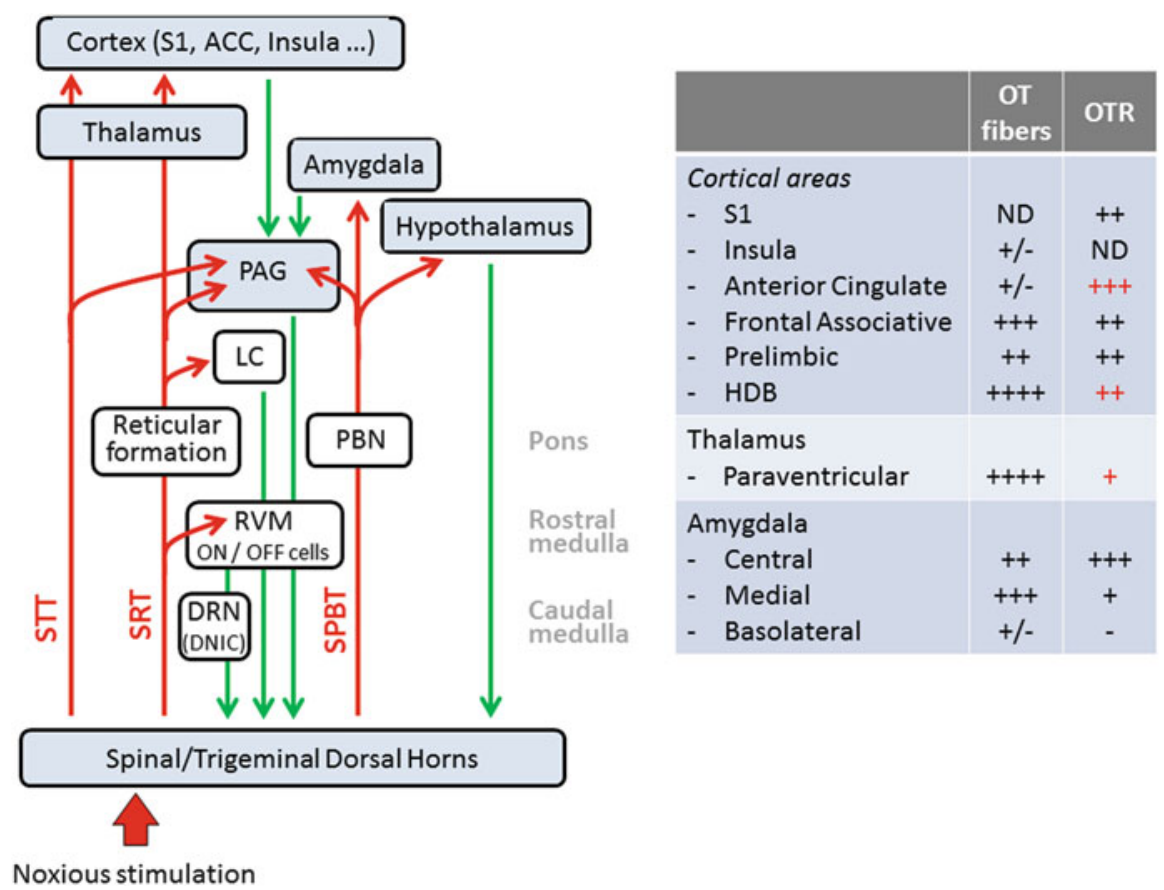

Fig. 1 Simplified diagram of major pain pathways and of key structures of the so-called "pain matrix." Ascending pathways are shown in red whereas descending pathways are shown in green. Structures highlighted have been shown to be innervated by OT fibers. Table on the right describes the cortical amygdala and thalamic regions of rodents innervated by OT fibers and the corresponding expression of OT receptors, if available. Text in red indicates that OT receptor expression has been confirmed in human samples. $L C$ locus coeruleus, $P A G$ periaqueducal gray, $P B N$ parabrachial nucleus, $R V M$ rostroventral medulla, $S R D$ subnuclear reticularis dorsalis, $H D B$ horizontal limb of the diagonal band of Broca

\section{Physiological and Behavioral Evidence}

The role of OT in pain modulation has long been controversial. Although the doses and administration methods used could have been different in the available literature, an anti-nociceptive effect of OT has been clearly demonstrated in healthy rats (Arletti et al. 1993; Lundeberg et al. 1994; Agren et al. 1995; Petersson et al. 1996; Juif and Poisbeau 2013) and in rodent models of inflammatory (Petersson et al. 2001; Yu et al. 2003; Juif et al. 2013) or neuropathic pain (Condes-Lara et al. 2005; Miranda-Cardenas et al. 2006).

In healthy rat, systemic (i.p. or s.c.) or central injections (i.c.v. or intracisternally) of OT increases the nociceptive thresholds to observe an aversive behavior when rodents were submitted to noxious thermal or mechanical stimulation. In some studies, these effects seemed to involve the endogenous opioid system as OT antinociception was completely or partially blocked by the administration of 
antagonists of opioid receptors (Arletti et al. 1993; Petersson et al. 1996; Yu et al. 2003). Recently, an antinociceptive effect of OT has been characterized after i.v. injection of OT in concentrations close to physiological (Juif and Poisbeau 2013).

The anti-nociceptive effect of OT was not only observed after application of exogenous OT. Several studies in rodents suggested that the OT system could be considered as a "homeostatic" inhibitory control limiting the transmission of nociceptive messages (Agren et al. 1995; Lund et al. 2002; Robinson et al. 2002). For example, electrical stimulation of the PVN significantly reduced pain symptoms in neuropathic rats (Miranda-Cardenas et al. 2006). Using optogenetic stimulation of spinal cord projecting parvOT neurons, a selective reduction in the nociceptive action potential discharge was also observed in deep dorsal horn neurons (Eliava et al. 2016). Finally, OT analgesia may also be obtained after stress, when OT concentration increases in the blood (Robinson et al. 2002; Juif and Poisbeau 2013).

\section{OT Neurons Involved in the Modulation of Pain}

\subsection{Magnocellular OT Neurons}

The central OT system in humans consists of about 35,000 neurons (Morton 1969; Wierda et al. 1991), corresponding to around 8,000 neurons in rats (Rhodes et al. 1981). Most OT producing neurons are located in the paraventricular (PVN), supraoptic (SON), and accessory nuclei and are large cells (20-30 mm in diameter). They are referred to as "magnocellular neurons" (magnOT; Fig. 2) and project to the posterior pituitary through which they release OT into the systemic blood circulation (Armstrong 1995; Burbach et al. 2001). Over decades, the magnOT neurons were the main focus of researchers as the main source of plasma OT, which induces constriction of smooth muscle cells in uterus and myoepithelial cells in mammary glands to elicit labor and milk let-down, respectively (Leng et al. 2015). However, very recently it was demonstrated that magnOT neurons, in addition to their projections to the posterior pituitary, also send the collaterals to vast majority forebrain regions to modulate brain-region specific behavior as fear expression (Knobloch et al. 2012) and the processing of social olfactory signals (Oettl et al. 2016). Furthermore, magnOT neurons project to various forebrain regions receiving somatosensory and pain signals. 


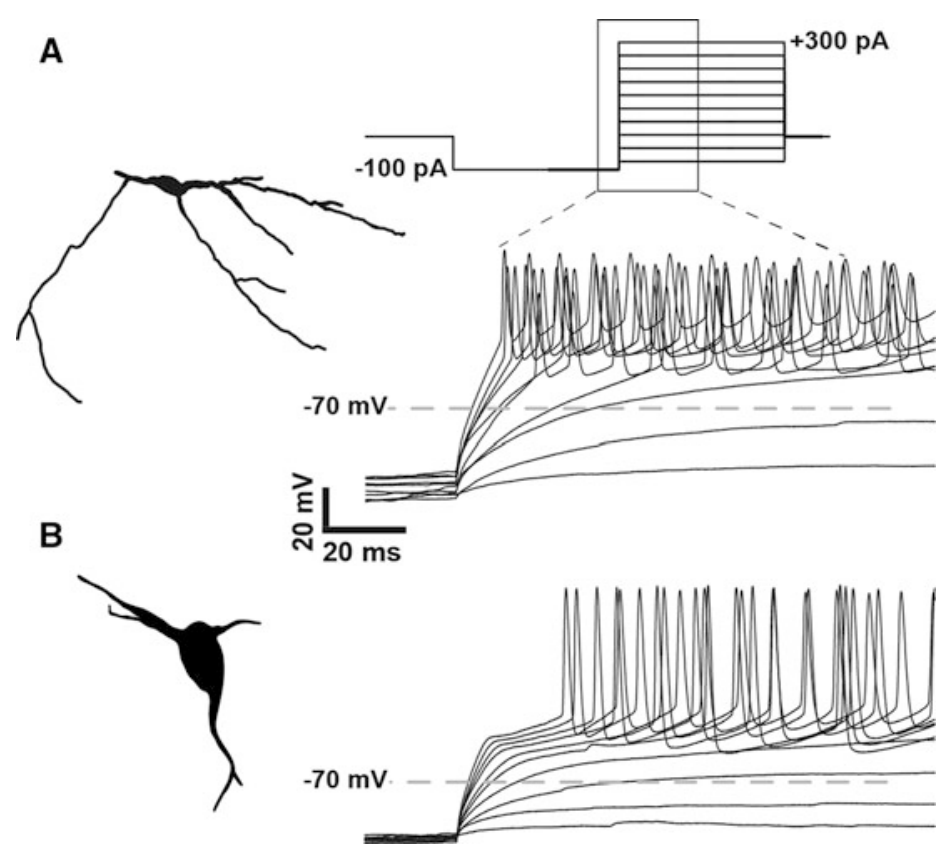

Fig. 2 Morphological and functional differences between magno- and parvocellular oxytocinergic neurons. (a) Parvocellular OT neuron. (b) Magnocellular neurons. Right traces: Current steps protocol starting from a hyperpolarizing current chosen to reach $-100 \mathrm{mV}$ (here $100 \mathrm{pA}$ ) followed by progressively more depolarizing current injections (upper trace). The representative changes in membrane potential for the parvOT and magnOT PVN neurons during the part of the current steps as indicated by the zoomed area are shown (lower traces). The ParvOT neurons (middle trace) do not display the transient outward rectification specific for the magnOT neurons (lower trace). From Eliava et al. (2016)

\subsection{Parvocellular OT Neurons}

Although magnOT neurons remain the primary subject of studies, Sawchenko and Swanson in the early 1980s demonstrated the existence of another population of OT neurons in the PVN, smaller than magnOT neurons, with a different shape of cell body and - most importantly - with projections to the spinal cord and several brain stem nuclei instead of projections to the posterior pituitary (Sawchenko and Swanson 1982). These cells were named "parvocellular or pre-autonomic neurons" (parvOT; Fig. 2), but were only sporadically studied due to their small number (total number is not counted so far) and difficulties with their identification, as they do not occupy a clearly boarded position in the PVN, but intermingle with other cell types (Swanson and Sawchenko 1983). However, studies on identified parvOT neurons have revealed that they are distinct not only in morphology and projection trajectories, but also in their electrophysiological characteristics: After injection of depolarizing currents in whole cell patch clamp configuration, parvOT neurons do 
not show the transient outward rectification that is typical for magnOT neurons (Luther et al. 2002; Eliava et al. 2016).

Based on specific projections of parvOT neurons to the brainstem (rostro-ventral medulla, nucleus tractus solitarius, dorsal vagal complex, and nucleus phrenicus) and spinal cord (intermediolateral cell column), several reports have demonstrated their contribution to the regulation of autonomic functions that modulate cardiovascular responses, respiration, and gastric motility (Geerling et al. 2010). These different effects suggested an anatomical and functional diversity of OT neurons. Most recently, we indeed demonstrated the existence of a specific subpopulation of about 30 parvOT neurons that project from the PVN to magnOT neurons in the ipsilateral and contralateral SON and, in addition, send axonal collaterals to sensory neurons of the spinal cord (Eliava et al. 2016). The optogenetic stimulation of the axons of these parvOT within the SON elicited firing of magnOT neurons and caused a robust increase of OT release into the blood (van den Burg et al. 2015). This suggested a role of this particular group of parvOT neurons in the coordination of activity of magnOT neurons in various situations, including modulation of pain perception.

\subsection{Circuits for Pain-Induced Activation of OT Neurons}

Although it was reported that somatic and visceral pain activates OT neurons (Ceccatelli et al. 1989; Wang et al. 2009; see also Fig. 3), there is very limited information on sensory projections onto OT neurons. Classical tracing studies with conventional anterograde tracer showed that neurons of the deep (II-X), but not superficial (I), layers of the spinal cord project to the caudo-dorsal part of the PVN (Gauriau and Bernard 2004), where parvOT neurons are located (Eliava et al.
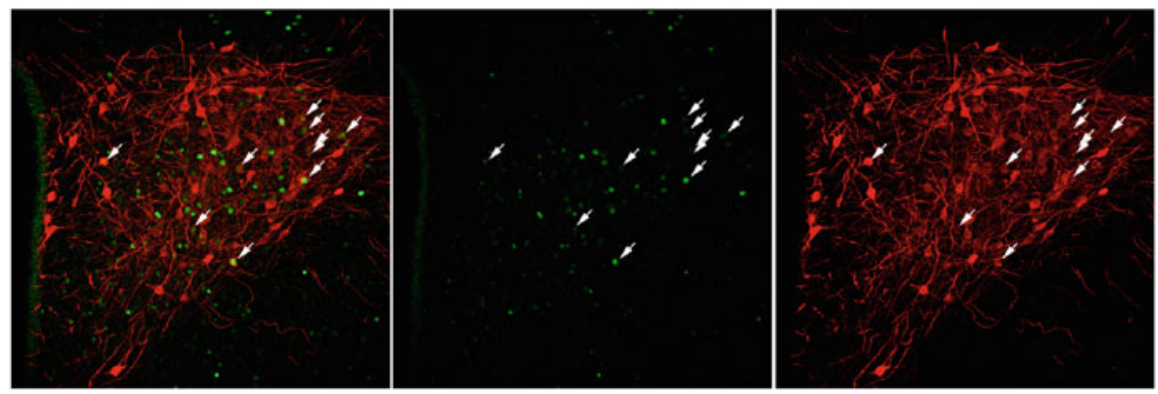

Fig. 3 OT neurons are activated by an acute pain. Left: merge; middle: c-fos (green); right: oxytocin $(r e d)$. A repeated acute pain stimulation (tail immersion in $46^{\circ} \mathrm{C}$ for $30 \mathrm{~s}$, three times, under isoflurane anesthesia) activates a subset of OT neurons, suggesting that only a subpopulation of OT neurons may react to a nociceptive stimulus. This raise the question of the involvement of this particular nociceptive-sensible OT neurons in pain processing. Unpublished materials from Charlet and Grinevich 
2016). In conjunction, two other anatomical studies have shown that the injection of wild-type rabies virus into the rat nipple resulted in the back-labeling of presumably parvOT neurons in the PVN (Gerendai et al. 2001; Koves et al. 2012). However, the use of multi-synaptically spreading rabies virus has precluded assessing whether spinal cord neurons that receive sensory information from nipples indeed directly terminate on parvOT neurons or whether they project indirectly [e.g., via brainstem nuclei, such as the nucleus tractus solitarius (Affleck et al. 2012)]. At the same time, no direct projections to OT neurons from amygdalar, thalamic, and cortical regions, associated with somatosensation/nociception, have been reported. As well, there is no information about OT cell types (i.e. ParvOT vs. MagnOT neurons) predominantly activated by pain.

\section{Supraspinal Structures Involved in Oxytocinergic Modulation of Pain}

Pain is a ubiquitous experience in animals, described by the International Association for the Study of Pain (IASP) as "an unpleasant sensory and emotional experience associated with actual or potential tissue damage or described in terms of such damage." The pain pathways consist of an ascending one, which convey the nociceptive signals from the periphery to the central nervous system, and a descending pathway, which projects onto different elements of the pathways to either increase or decrease in nociception. The ensembles of involved structures are called the "pain matrix," which is affected by OT by combined peripheral and central mechanisms (Tracy et al. 2015).

A decade ago, it was shown that central (i.c.v.) injection of OT can alleviate pain (Yang et al. 2007). More recently, it was reported that OT axons innervate structures of the "pain matrix" (Fig. 1) and OT was shown to have a pain-related effect via PAG (Ge et al. 2002), nucleus raphe magnus (Wang et al. 2003), nucleus accumbens (Gu and Yu 2007), and central amygdala (Han and Yu 2009), while few evidences obtained in humans show oxytocin pain-related effects in the cortical areas (Bos et al. 2015).

\subsection{Cortex}

Functional neuroimaging approaches in humans show a robust activation in the cortical structures of the pain matrix, mainly insula and sensorimotor regions, when subjects were asked to observe pain in others. As this activation was strongly reduced after intranasal OT, the authors conclude that OT may decrease empathy for pain (Bos et al. 2015). However, while OT fibers are highly present in a number 
of pain-related cortical regions (Knobloch et al. 2012; Fig. 1) their putative analgesic role is still to be deciphered.

\subsection{Central Amygdala}

The central amygdala is a key component in the pain matrix that assigns emotional to salient external stimuli (Sah et al. 2003) and is thus a key structure in the regulation of pain and its associated mood alterations (Neugebauer et al. 2009). Viviani and colleagues showed that OT responsive CeL interneurons can selectively gate different responses (to fear in this case) by acting on a subpopulation of projection neurons of the CeM (Viviani et al. 2011). The physiological relevance of such regulation of $\mathrm{CeA}$ by OT was further tested. Using optogenetics to allow specific activation of the axons of OT neurons, Knobloch and colleagues showed that activation of OT axons in the CeL elicited the same responses in CeA GABAergic neurons as did exogenous applications, but revealed a further glutamatergic component in this response (Knobloch et al. 2012). In a contextual fear conditioning paradigm, they could reduce freezing by optogenetic activation of OT axons in the $\mathrm{CeL}$, demonstrating that the sparse OT fibers innervating the $\mathrm{CeL}$ are sufficient to elicit a drastic change in behavior in the rat (Knobloch et al. 2012). Because of the strong link between pain and anxiety, as well as the known involvement of CeA in pain modulation, one can speculate about the important and complex analgesic function of OT release in this structure. Accordingly, Han and Yu demonstrated an analgesic effect of intra-CeA infusion of oxytocin (Han and Yu 2009). In the same supportive line of evidence, Neugebauer's lab recently published interesting results suggesting that the CeA OTR mediates some analgesic tone in an arthrisis pain model (Cragg et al. 2016).

\subsection{PAG}

The PAG and the rostral ventromedial medulla are highly connected and are key centers of descending pain pathways (Heinricher et al. 2009). It has been shown that painful stimulations are able to elevate the OT content in the PAG (Yang et al. 2011a). In addition, intra-PAG injection of OT can increase mechanical nociceptive threshold in naïve rats (Yang et al. 2011b). However, as oxytocin at the concentrations used can bind both OTR and V1A-R, further experiments have to be conducted to determine both the involvement of OTR itself as well as of endogenous oxytocin in pain control through modification of PAG activity. Finally, the precise circuitry involved in such an antinociceptive effect is currently unknown, as are the potential analgesic effects of oxytocin in a painful situation. 


\subsection{Raphe Nuclei}

Raphe magnus has been reported as a potent target of the OT-mediated analgesic system, as direct infusion within the raphe magnus induces strong analgesia (Wang et al. 2003). Interestingly, the serotoninergic system is also involved in OT pain modulation and indeed the raphe nuclei shows increase in $c$-fos after PVN stimulation known to induce anti-nociception in SC (Condes-Lara et al. 2015). Serotonin intrathecal injection mimics the OT effect and can potentiate its anti/nociceptive effect if administrated together. In addition, OT injection in the raphe magnus also reduces anxiety (Yoshida et al. 2009). This is of particular interest because pain is a complex feeling, involving both somatosensory and emotional components. In humans, intranasal OT administration resulted in a decrease of anxiety and improved trust (Heinrichs et al. 2003; Kirsch et al. 2005). As chronic pain is linked to the development of anxio-depressive symptoms (Asmundson and Katz 2009) and knowing the various effects of central and peripheral OT on both, some crucial therapies might emerge through a better comprehension of the OT system in the CNS.

\subsection{Nucleus Accumbens}

A striking example of the dramatic role induced by a subtle change in OT signaling is well illustrated in the nucleus accumbens. Indeed, changes of OTR expression on reproductive/social behavior drives the variation in OTR expression in the nucleus accumbens of voles, making them either monogamous (prairie voles, more OT-binding) or polygamous (mountain voles, less OT-binding) (Insel and Shapiro 1992). Interestingly, Gu and Yu suggested a dose-dependent antinociceptive action of OT when directly infused in the nucleus accumbens (Gu and Yu 2007). While this mechanism of action is still unclear regarding which receptor it activates or which pathways it recruits, this data is very interesting in the view of the physiological and rhythmic variability of OTR expression, as exemplified by Insel and Shapiro.

\section{Spinal Structures Involved in Oxytocinergic Modulation of Nociception}

\subsection{Oxytocinergic Modulation of Spinal Network}

The spinal cord is one of the CNS regions where there is a perfect overlap between the oxytocinergic axonal innervation and OT binding sites (Fig. 4). ParvOT project their axons in areas of the spinal cord known to process nociceptive and 
Immunohistochemistry

(neurophysin-OT labeling)

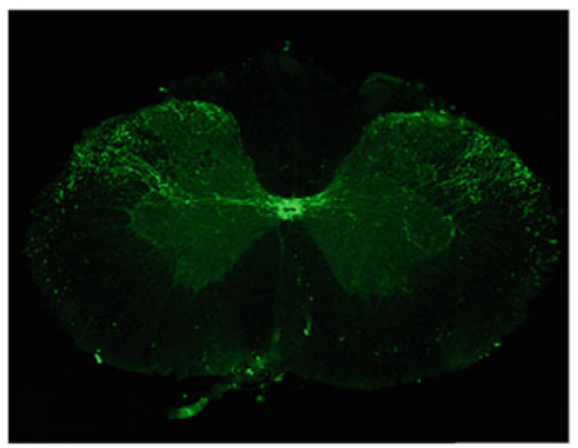

Superficial layers (I)

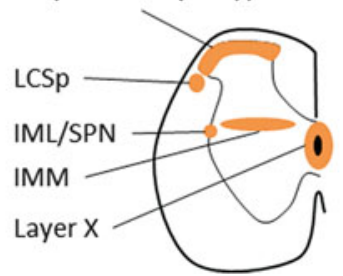

\section{Autoradiography} (dOVT-125 binding)

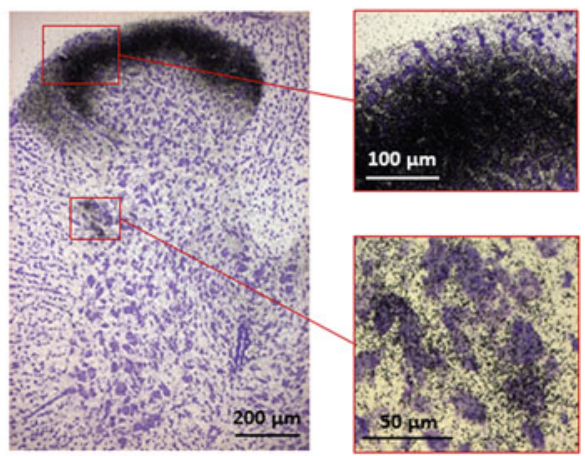

Superficial layers (I)

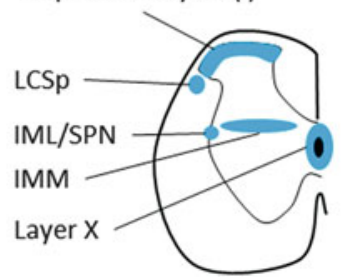

Fig. 4 Oxytocin in spinal cord. Immunohistochemistry of neurophysin I-(OT) immunoreactive axons in the spinal cord (left) and autoradiography of OT binding sites (right) using the radiolabeled selective antagonist dOVT-I ${ }^{125}$ (right) illustrating the perfect overlap in the superficial layers (layer I-II), lateral corticospinal tractus (LCSp), intermedio-lateral (IML), and intermediomedial (IMM) nuclei and layer X. Adapted from Breton et al. (2008); unpublished materials from Charlet and Grinevich

non-nociceptive somatic (layer I, II) and visceral informations (layer X, spinal lateral nucleus). Projection areas are also located in the intermediate spinal cord gray matter, i.e., specifically those processing sympathetic (intermedio-lateral columns (ilc) and intermedio-median autonomous area (ima) around the central canal) and parasympathetic autonomic formations (e.g., sacral parasympathetic nucleus). As illustrated in Fig. 4, these areas perfectly overlap with OT binding sites detected by histoautoradiography (Reiter et al. 1994; VeronneauLongueville et al. 1999; Uhl-Bronner et al. 2005).

OT innervation in rats is particularly abundant around the thoracic and lumbar segments. In agreement, radioimmunoassay revealed that OT spinal content was also significantly higher in these particular spinal segments (Juif et al. 2013). Finally, the density of OT binding in superficial layers I and II of the lumbar segments was significantly higher in L4 and L6 compared to the others, when quantified by autoradiography. Together, these data provide an anatomical support for a direct modulation of spinal cord neurons by parvOT neurons, possibly affecting nociceptive and autonomic processing. It is interesting to note that OTergic synapses in the superficial layers could be visualized in electron microscopy (Rousselot 
et al. 1990), although no information was given on the neurochemical nature of the postsynaptic neurons. Electrophysiological experiments revealed that OT-sensitive neurons could be of glutamatergic nature. A presynaptic excitation of glutamatergic transmission was found after infusion of OT in primary cultures of layer I-III rat spinal cord neurons (Jo et al. 1998). OT-activated spinal cord neurons, revealed by c-fos expression, were always non-GABAergic neurons in acute rat slices (Breton et al. 2008). It was further shown that in lamina II, OTR activation reduces the firing of neurons exhibiting a depolarization-induced bursting firing pattern and has no effect on the single spike firing pattern cells (Breton et al. 2009). Of importance, it seems that the AVP system is not involved in those effects of OT at the spinal level (Rojas-Piloni et al. 2010). Those effects of exogenous OT can also be observed by stimulation of the descending OT projections from the PVN: while recording the nociceptive $\mathrm{A} \delta$ and $\mathrm{C}$ evoked discharge, Condès-Lara and colleagues demonstrated a reduction of the duration of such discharge by raw electrical stimulation of the PVN (Condes-Lara et al. 2006; see also Fig. 5). In vivo studies by DeLaTorre and colleagues further showed that exogenous OT or endogenous OT released through PVN stimulation could reduce or prevent the LTP in spinal wide dynamic range neurons (DeLaTorre et al. 2009). The analgesic role of endogenous release of OT in the spinal cord was further demonstrated and extended to lamina X, imc and ima: about 30 parvOT neurons can both control magnOT-mediated OT blood release and directly target deep layer WDR neurons to ensure a coordinated and complementary effect of peripheral and central release of OT on nociception (Eliava et al. 2016). Finally, these findings can be translated into human clinics as intrathecal OT injections successfully reduce both low-back (Yang 1994) and visceral (Engle et al. 2012) pain.

Interestingly, here the OT system seems to be in strong interaction with several others. For example, the long-lasting analgesia induced by OT is mediated by a strong neurosteroidogenesis, which leads to increase $\mathrm{GABA}_{\mathrm{A}}$ mediated inhibition in lamina II neurons (Juif et al. 2013). This model explains the transition from acute to chronic pain by potentiation (LTP) of nociceptive neurons after repeated noxious stimuli (or other mechanisms), which strengthen further the nociceptive signals. In addition, $\mu$-opioid receptor seems to be involved in the OT-mediated analgesic effect as their blockade do partially block the effect of either OT application or PVN stimulation (Miranda-Cardenas et al. 2006; Condes-Lara et al. 2009). Similarly, another study showed the participation of mu and kappa opioid receptors in the antinociceptive effect of OT in an inflammatory pain model (Yu et al. 2003).

\subsection{Mechanisms for Spinal Antinociception}

Neurons in the superficial layers of the dorsal horn spinal cord play a fundamental role in nociceptive processing, since they are the first relay for "nociceptive messages" transmitted by sensory afferent fibers type A $\delta$ and C (Poisbeau 2016). They are also the target for descending controls including parvOT axonal terminals 


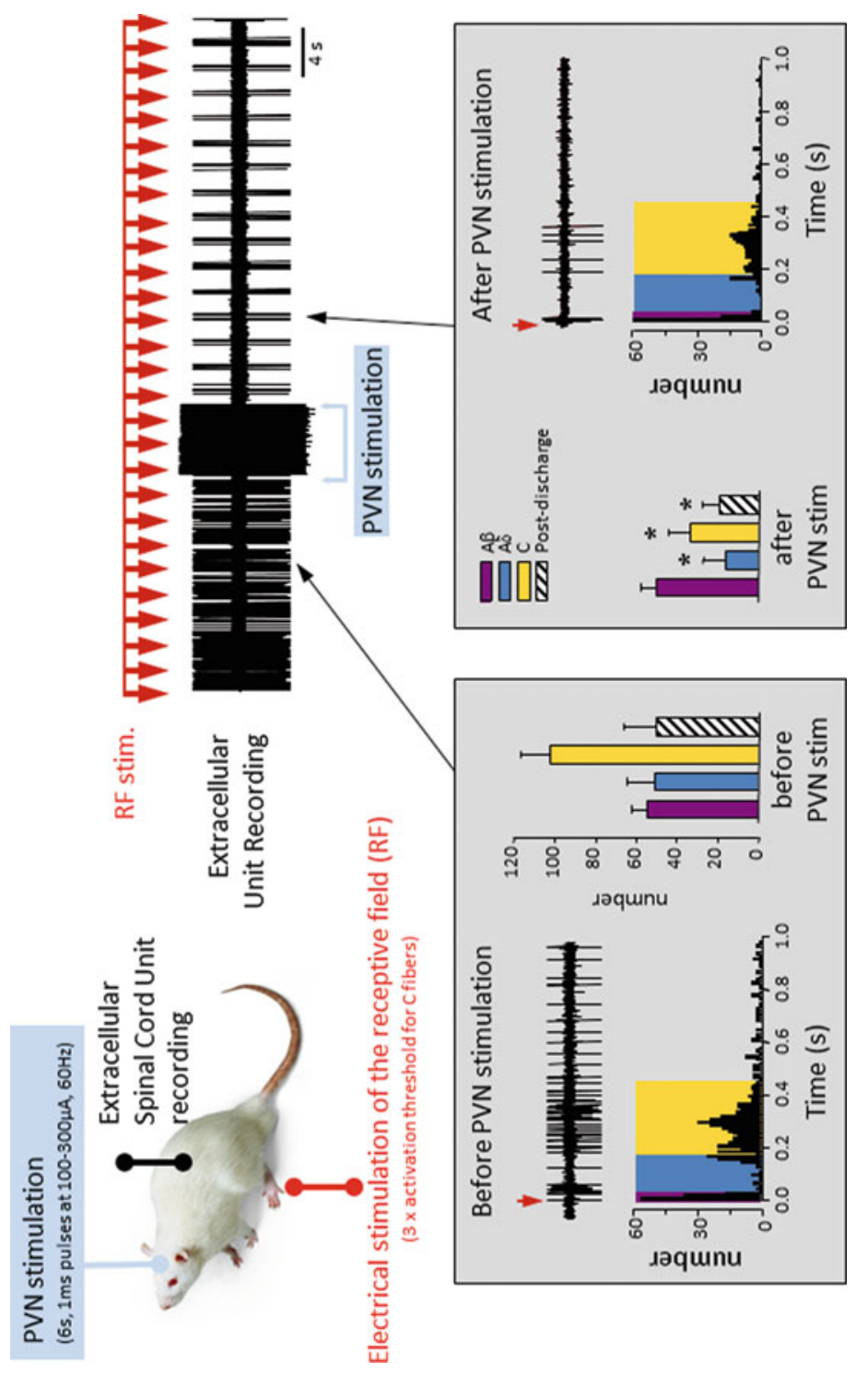

욜

䒠 岂

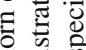

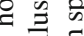

क्ष

흔

年

¿

인

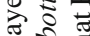

의

安这

$\Xi \dot{0}$

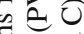

훌

导

흥 䒕

$\overrightarrow{0}$

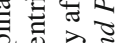

का

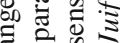

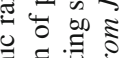

츨 을

극 흥.

$\otimes$.

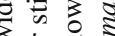

3 的

可

恶焉施

రั

D

후요

矛 寻

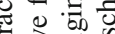

: $: \because$

i 웡

范

3 뭉

范

के

๘

पै口

음 훙

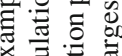

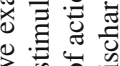

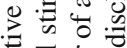

可过

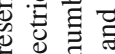

형

$\widetilde{2} \circlearrowright$

的青

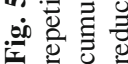


secreting OT. Using patch-clamp electrophysiology in spinal cord slice combined to c-fos expression, OT has been shown to excite a subpopulation of glutamatergic interneurons (Breton et al. 2008). Interestingly, these OT-sensitive excitatory interneurons were apparently responsible for the recruitment of all GABAergic interneurons, thus inducing a general increase in inhibition in the superficial layers. In addition to a possible presynaptic inhibition on nociceptive primary afferent fibers, this mode of action of OT could be sufficient to explain the selective blockade of A $\delta$ and C-type nociceptive messages.

So far, it has been impossible to observe any calcium concentration increase in spinal cord neurons and the detailed mechanism of action is still not fully understood. In the short term, it seems that OTR activation can rapidly inhibit transient potassium current $\left(\mathrm{I}_{\mathrm{A}}\right)$ and reduce the firing ability of some spinal cord neurons expressing this channel (Breton et al. 2009). This reduction of neuronal firing is interesting since it will (1) contribute to the general decrease in interneuronal network ongoing activity without affecting the amplified inhibitory synaptic activity and, (2) reduce (or prevent) the integration of nociceptive messages by projection neurons located in lamina I and V (deep layers). This hypothesis has been indeed verified while recording neurokinin 1 receptor (NK1R) positive wide dynamic range neurons in lamina V, exposed to OT (Eliava et al. 2016). These NK1R neurons in lamina $\mathrm{V}$ could even express OTR, as shown in this study.

A remaining open question was related to a possible long-lasting analgesic effect of OT. In inflammatory pain states, OT content in the spinal cord remained elevated for several days (Juif et al. 2013). In this study, a novel mechanism has been proposed where OTR activation exerts a tonic activation of extracellular regulated kinases type and stimulates the production of the neuroactive neurosteroid allopregnanolone. Local increase in allopregnanolone concentration perfectly explained the persistence of an elevated inhibition mediated by prolonged GABAA receptor-mediated synaptic currents and reduction in membrane resistance due to tonic extrasynaptic GABAA receptor activation.

\section{Conclusion}

After more than two decades of work, there is nowadays a large number of studies supporting OT analgesic action in the central nervous system. For practical reasons, and also because the spinal cord contains second order neurons receiving peripheral "pain messages," spinal antinociception has been well characterized. Apart from its sensory component (i.e., nociception), pain is an emotion giving rise to robust aversive behaviors and long-lasting cognitive imprinting. Recent progress has been made by analyzing the role of OT in CNS structures processing emotion such as fear and anxiety. The benefits of OT in limiting fear expression and anxiety is undeniable and may contribute, for a large part, to the limitation of pain expression in physiological and pathological conditions. It is, however, unclear how, to what extent, and on which component OT can modulate pain expression at this stage. In 
particular, the role of OT on rewarding processes and memory reinforcement remains to be unraveled. This question is obviously a critical issue when considering labor pain and possibly other visceral pain conditions which are particularly difficult to treat.

The clinical interest of using OT as a painkiller in pathological pain states has then to be considered. Two studies are already available and have been highly discussed. The first one attempted to alleviate pain symptoms in fibromyalgic female patients and was inconclusive at a daily administration dose of 80 IU for 3 weeks (Mameli et al. 2014). In the second study, two patients suffering from refractory cancer pain reported to have less pain symptoms after epidural injection of about $2 \mu \mathrm{g}$ of OT (Condes-Lara et al. 2016). Of course, these two studies are too preliminary to conclude. The future human studies with larger cohorts, pertinent administration procedures, and appropriate design will, for sure, be of significant interest to propose (or not) OT treatment to pain patients.

Among the remaining open questions, a subject is now appearing: a possible analgesic role of OT at the periphery. Indeed, it appears that some small diameter sensory neurons (i.e., C-type nociceptors) do express OT receptor (Moreno-Lopez et al. 2013), explaining nicely antinociception observed after intravenous OT injection (Juif and Poisbeau 2013) or optogenetic-driven endogenous release from SON (Eliava et al. 2016). A similar conclusion was reached while studying the trigeminal ganglia in the context of migraine (Tzabazis et al. 2016). In addition to what has been already shown in the central nervous system, these recent results on peripheral OT receptor activation provide a great hope of therapeutic benefit for patients suffering from migraine and other primary headache disorders.

\section{References}

Acher R, Fromageot C (1955) Chemistry of posterior-pituitary hormones. Ergeb Physiol 48: 286-327

Affleck VS, Coote JH, Pyner S (2012) The projection and synaptic organisation of NTS afferent connections with presympathetic neurons, GABA and nNOS neurons in the paraventricular nucleus of the hypothalamus. Neuroscience 219:48-61

Agren G, Lundeberg T, Uvnas-Moberg K, Sato A (1995) The oxytocin antagonist 1-deamino-2-DTyr-(Oet)-4-Thr-8-Orn-oxytocin reverses the increase in the withdrawal response latency to thermal, but not mechanical nociceptive stimuli following oxytocin administration or massagelike stroking in rats. Neurosci Lett 187(1):49-52

Arletti R, Benelli A, Bertolini A (1993) Influence of oxytocin on nociception and morphine antinociception. Neuropeptides 24(3):125-129

Armstrong WE (1995) Morphological and electrophysiological classification of hypothalamic supraoptic neurons. Prog Neurobiol 47(4-5):291-339

Asmundson GJ, Katz J (2009) Understanding the co-occurrence of anxiety disorders and chronic pain: state-of-the-art. Depress Anxiety 26(10):888-901

Blume A, Bosch OJ, Miklos S, Torner L, Wales L, Waldherr M, Neumann ID (2008) Oxytocin reduces anxiety via ERK1/2 activation: local effect within the rat hypothalamic paraventricular nucleus. Eur J Neurosci 27(8):1947-1956 
Bos PA, Montoya ER, Hermans EJ, Keysers C, van Honk J (2015) Oxytocin reduces neural activity in the pain circuitry when seeing pain in others. NeuroImage 113:217-224

Bosch OJ, Young LJ (2017) Oxytocin and social relationships: from attachment to bond disruption. Curr Top Behav Neurosci. https://doi.org/10.1007/7854_2017_10

Breton JD, Veinante P, Uhl-Bronner S, Vergnano AM, Freund-Mercier MJ, Schlichter R, Poisbeau $\mathrm{P}$ (2008) Oxytocin-induced antinociception in the spinal cord is mediated by a subpopulation of glutamatergic neurons in lamina I-II which amplify GABAergic inhibition. Mol Pain 4:19

Breton JD, Poisbeau P, Darbon P (2009) Antinociceptive action of oxytocin involves inhibition of potassium channel currents in lamina II neurons of the rat spinal cord. Mol Pain 5:63

Burbach JP, Luckman SM, Murphy D, Gainer H (2001) Gene regulation in the magnocellular hypothalamo-neurohypophysial system. Physiol Rev 81(3):1197-1267

Busnelli M, Chini B (2017) Molecular basis of oxytocin receptor signalling in the brain: what we know and what we need to know. Curr Top Behav Neurosci. https://doi.org/10.1007/7854_ 2017_6

Busnelli M, Sauliere A, Manning M, Bouvier M, Gales C, Chini B (2012) Functional selective oxytocin-derived agonists discriminate between individual $\mathrm{G}$ protein family subtypes. J Biol Chem 287(6):3617-3629

Ceccatelli S, Villar MJ, Goldstein M, Hokfelt T (1989) Expression of c-Fos immunoreactivity in transmitter-characterized neurons after stress. Proc Natl Acad Sci U S A 86(23):9569-9573

Condes-Lara M, Maie IA, Dickenson AH (2005) Oxytocin actions on afferent evoked spinal cord neuronal activities in neuropathic but not in normal rats. Brain Res 1045(1-2):124-133

Condes-Lara M, Rojas-Piloni G, Martinez-Lorenzana G, Rodriguez-Jimenez J, Lopez Hidalgo M, Freund-Mercier MJ (2006) Paraventricular hypothalamic influences on spinal nociceptive processing. Brain Res 1081(1):126-137

Condes-Lara M, Rojas-Piloni G, Martinez-Lorenzana G, Rodriguez-Jimenez J (2009) Paraventricular hypothalamic oxytocinergic cells responding to noxious stimulation and projecting to the spinal dorsal horn represent a homeostatic analgesic mechanism. Eur J Neurosci 30(6):1056-1063

Condes-Lara M, Martinez-Lorenzana G, Rubio-Beltran E, Rodriguez-Jimenez J, Rojas-Piloni G, Gonzalez-Hernandez A (2015) Hypothalamic paraventricular nucleus stimulation enhances c-Fos expression in spinal and supraspinal structures related to pain modulation. Neurosci Res 98:59-63

Condes-Lara M, Zayas-Gonzalez H, Manzano-Garcia A, Cordova-Quiroz E, Granados-Mortera J, Garcia-Cuevas M, Morales-Gomez J, Gonzalez-Hernandez A (2016) Successful pain management with epidural oxytocin. CNS Neurosci Ther 22(6):532-534

Cragg B, Ji G, Neugebauer V (2016) Differential contributions of vasopressin V1A and oxytocin receptors in the amygdala to pain-related behaviors in rats. Mol Pain 12

DeLaTorre S, Rojas-Piloni G, Martinez-Lorenzana G, Rodriguez-Jimenez J, Villanueva L, Condes-Lara M (2009) Paraventricular oxytocinergic hypothalamic prevention or interruption of long-term potentiation in dorsal horn nociceptive neurons: electrophysiological and behavioral evidence. Pain 144(3):320-328

du Vigneaud V (1954-1955) Hormones of the posterior pituitary gland: oxytocin and vasopressin. Harvey Lect 50:1-26

Eliava M, Melchior M, Knobloch-Bollmann HS, Wahis J, da Silva Gouveia M, Tang Y, Ciobanu AC, Triana del Rio R, Roth LC, Althammer F, Chavant V, Goumon Y, Gruber T, Petit-Demouliere N, Busnelli M, Chini B, Tan LL, Mitre M, Froemke RC, Chao MV, Giese G, Sprengel R, Kuner R, Poisbeau P, Seeburg PH, Stoop R, Charlet A, Grinevich V (2016) A new population of parvocellular oxytocin neurons controlling magnocellular neuron activity and inflammatory pain processing. Neuron 89(6):1291-1304

Engle MP, Ness TJ, Robbins MT (2012) Intrathecal oxytocin inhibits visceromotor reflex and spinal neuronal responses to noxious distention of the rat urinary bladder. Reg Anesth Pain Med 37(5):515-520 
Gauriau C, Bernard JF (2004) A comparative reappraisal of projections from the superficial laminae of the dorsal horn in the rat: the forebrain. J Comp Neurol 468(1):24-56

Ge Y, Lundeberg T, Yu LC (2002) Blockade effect of mu and kappa opioid antagonists on the antinociception induced by intra-periaqueductal grey injection of oxytocin in rats. Brain Res 15; 927(2):204-207

Geerling JC, Shin JW, Chimenti PC, Loewy AD (2010) Paraventricular hypothalamic nucleus: axonal projections to the brainstem. J Comp Neurol 518(9):1460-1499

Gerendai I, Toth IE, Kocsis K, Boldogkoi Z, Medveczky I, Halasz B (2001) Transneuronal labelling of nerve cells in the CNS of female rat from the mammary gland by viral tracing technique. Neuroscience 108(1):103-118

Gravati M, Busnelli M, Bulgheroni E, Reversi A, Spaiardi P, Parenti M, Toselli M, Chini B (2010) Dual modulation of inward rectifier potassium currents in olfactory neuronal cells by promiscuous G protein coupling of the oxytocin receptor. J Neurochem 114(5):1424-1435

$\mathrm{Gu}$ XL, Yu LC (2007) Involvement of opioid receptors in oxytocin-induced antinociception in the nucleus accumbens of rats. J Pain 8(1):85-90

Han Y, Yu LC (2009) Involvement of oxytocin and its receptor in nociceptive modulation in the central nucleus of amygdala of rats. Neurosci Lett 454(1):101-104

Heinricher MM, Tavares I, Leith JL, Lumb BM (2009) Descending control of nociception: specificity, recruitment and plasticity. Brain Res Rev 60(1):214-225

Heinrichs M, Baumgartner T, Kirschbaum C, Ehlert U (2003) Social support and oxytocin interact to suppress cortisol and subjective responses to psychosocial stress. Biol Psychiatry 54(12): 1389-1398

Insel TR, Shapiro LE (1992) Oxytocin receptor distribution reflects social organization in monogamous and polygamous voles. Proc Natl Acad Sci U S A 89(13):5981-5985

Jo YH, Stoeckel ME, Freund-Mercier MJ, Schlichter R (1998) Oxytocin modulates glutamatergic synaptic transmission between cultured neonatal spinal cord dorsal horn neurons. J Neurosci 18(7):2377-2386

Juif PE, Poisbeau P (2013) Neurohormonal effects of oxytocin and vasopressin receptor agonists on spinal pain processing in male rats. Pain 154(8):1449-1456

Juif PE, Breton JD, Rajalu M, Charlet A, Goumon Y, Poisbeau P (2013) Long-lasting spinal oxytocin analgesia is ensured by the stimulation of allopregnanolone synthesis which potentiates GABA(A) receptor-mediated synaptic inhibition. J Neurosci 33(42):16617-16626

Jurek B, Slattery DA, Maloumby R, Hillerer K, Koszinowski S, Neumann ID, van den Burg EH (2012) Differential contribution of hypothalamic MAPK activity to anxiety-like behaviour in virgin and lactating rats. PLoS One 7(5):e37060

Kimura T, Tanizawa O, Mori K, Brownstein MJ, Okayama H (1992) Structure and expression of a human oxytocin receptor. Nature 356(6369):526-529

Kirsch P, Esslinger C, Chen Q, Mier D, Lis S, Siddhanti S, Gruppe H, Mattay VS, Gallhofer B, Meyer-Lindenberg A (2005) Oxytocin modulates neural circuitry for social cognition and fear in humans. J Neurosci 25(49):11489-11493

Knobloch HS, Charlet A, Hoffmann LC, Eliava M, Khrulev S, Cetin AH, Osten P, Schwarz MK, Seeburg PH, Stoop R, Grinevich V (2012) Evoked axonal oxytocin release in the central amygdala attenuates fear response. Neuron 73(3):553-566

Koves K, Gyorgyi Z, Szabo FK, Boldogkoi Z (2012) Characterization of the autonomic innervation of mammary gland in lactating rats studied by retrograde transynaptic virus labeling and immunohistochemistry. Acta Physiol Hung 99(2):148-158

Lee HJ, Macbeth AH, Pagani JH, Young WS 3rd (2009) Oxytocin: the great facilitator of life. Prog Neurobiol 88(2):127-151

Leng G, Pineda R, Sabatier N, Ludwig M (2015) 60 years of neuroendocrinology: the posterior pituitary, from Geoffrey Harris to our present understanding. J Endocrinol 226(2):T173-T185

Lund I, Ge Y, Yu LC, Uvnas-Moberg K, Wang J, Yu C, Kurosawa M, Agren G, Rosen A, Lekman M, Lundeberg T (2002) Repeated massage-like stimulation induces long-term effects on nociception: contribution of oxytocinergic mechanisms. Eur J Neurosci 16(2):330-338 
Lundeberg T, Uvnas-Moberg K, Agren G, Bruzelius G (1994) Anti-nociceptive effects of oxytocin in rats and mice. Neurosci Lett 170(1):153-157

Luther JA, Daftary SS, Boudaba C, Gould GC, Halmos KC, Tasker JG (2002) Neurosecretory and non-neurosecretory parvocellular neurones of the hypothalamic paraventricular nucleus express distinct electrophysiological properties. J Neuroendocrinol 14(12):929-932

Mameli S, Pisanu GM, Sardo S, Marchi A, Pili A, Carboni M, Minerba L, Trincas G, Carta MG, Melis MR, Agabio R (2014) Oxytocin nasal spray in fibromyalgic patients. Rheumatol Int 34(8):1047-1052

Miranda-Cardenas Y, Rojas-Piloni G, Martinez-Lorenzana G, Rodriguez-Jimenez J, LopezHidalgo M, Freund-Mercier MJ, Condes-Lara M (2006) Oxytocin and electrical stimulation of the paraventricular hypothalamic nucleus produce antinociceptive effects that are reversed by an oxytocin antagonist. Pain 122(1-2):182-189

Moreno-Lopez Y, Martinez-Lorenzana G, Condes-Lara M, Rojas-Piloni G (2013) Identification of oxytocin receptor in the dorsal horn and nociceptive dorsal root ganglion neurons. Neuropeptides 47(2):117-123

Morton A (1969) A quantitative analysis of the normal neuron population of the hypothalamic magnocellular nuclei in man and of their projections to the neurohypophysis. J Comp Neurol 136(2):143-157

Neugebauer V, Galhardo V, Maione S, Mackey SC (2009) Forebrain pain mechanisms. Brain Res Rev 60(1):226-242

Oettl LL, Ravi N, Schneider M, Scheller MF, Schneider P, Mitre M, da Silva Gouveia M, Froemke RC, Chao MV, Young WS, Meyer-Lindenberg A, Grinevich V, Shusterman R, Kelsch W (2016) Oxytocin enhances social recognition by modulating cortical control of early olfactory processing. Neuron 90(3):609-621

Petersson M, Alster P, Lundeberg T, Uvnas-Moberg K (1996) Oxytocin increases nociceptive thresholds in a long-term perspective in female and male rats. Neurosci Lett 212(2):87-90

Petersson M, Wiberg U, Lundeberg T, Uvnas-Moberg K (2001) Oxytocin decreases carrageenan induced inflammation in rats. Peptides 22(9):1479-1484

Poisbeau P (2016) Spinal cord mechanisms in acute and chronic pain states. In: Sommer CL, Wallace MS, Cohen SP, Kress M (eds) Pain 2016 refresher course. IASP Press, Washington, pp 27-34

Reiter MK, Kremarik P, Freund-Mercier MJ, Stoeckel ME, Desaulles E, Feltz P (1994) Localization of oxytocin binding sites in the thoracic and upper lumbar spinal cord of the adult and postnatal rat: a histoautoradiographic study. Eur J Neurosci 6(1):98-104

Rhodes CH, Morrell JI, Pfaff DW (1981) Immunohistochemical analysis of magnocellular elements in rat hypothalamus: distribution and numbers of cells containing neurophysin, oxytocin, and vasopressin. J Comp Neurol 198(1):45-64

Robinson DA, Wei F, Wang GD, Li P, Kim SJ, Vogt SK, Muglia LJ, Zhuo M (2002) Oxytocin mediates stress-induced analgesia in adult mice. J Physiol 540(Pt 2):593-606

Rojas-Piloni G, Mejia-Rodriguez R, Martinez-Lorenzana G, Condes-Lara M (2010) Oxytocin, but not vassopressin, modulates nociceptive responses in dorsal horn neurons. Neurosci Lett 476(1):32-35

Rousselot P, Papadopoulos G, Merighi A, Poulain DA, Theodosis DT (1990) Oxytocinergic innervation of the rat spinal cord. An electron microscopic study. Brain Res 529(1-2):178-184

Sah P, Faber ES, Lopez De Armentia M, Power J (2003) The amygdaloid complex: anatomy and physiology. Physiol Rev 83(3):803-834

Sawchenko PE, Swanson LW (1982) Immunohistochemical identification of neurons in the paraventricular nucleus of the hypothalamus that project to the medulla or to the spinal cord in the rat. J Comp Neurol 205(3):260-272

Stoop R (2012) Neuromodulation by oxytocin and vasopressin. Neuron 76(1):142-159

Swanson LW, Sawchenko PE (1983) Hypothalamic integration: organization of the paraventricular and supraoptic nuclei. Annu Rev Neurosci 6:269-324 
Tracy LM, Georgiou-Karistianis N, Gibson SJ, Giummarra MJ (2015) Oxytocin and the modulation of pain experience: implications for chronic pain management. Neurosci Biobehav Rev 55:53-67

Tzabazis A, Mechanic J, Miller J, Klukinov M, Pascual C, Manering N, Carson DS, Jacobs A, Qiao Y, Cuellar J, Frey WH 2nd, Jacobs D, Angst M, Yeomans DC (2016) Oxytocin receptor: expression in the trigeminal nociceptive system and potential role in the treatment of headache disorders. Cephalalgia 36(10):943-950

Uhl-Bronner S, Waltisperger E, Martinez-Lorenzana G, Condes Lara M, Freund-Mercier MJ (2005) Sexually dimorphic expression of oxytocin binding sites in forebrain and spinal cord of the rat. Neuroscience 135(1):147-154

van den Burg EH, Stindl J, Grund T, Neumann ID, Strauss O (2015) Oxytocin stimulates extracellular $\mathrm{Ca} 2+$ influx through TRPV2 channels in hypothalamic neurons to exert its anxiolytic effects. Neuropsychopharmacology 40(13):2938-2947

Veronneau-Longueville F, Rampin O, Freund-Mercier MJ, Tang Y, Calas A, Marson L, McKenna KE, Stoeckel ME, Benoit G, Giuliano F (1999) Oxytocinergic innervation of autonomic nuclei controlling penile erection in the rat. Neuroscience 93(4):1437-1447

Viviani D, Charlet A, van den Burg E, Robinet C, Hurni N, Abatis M, Magara F, Stoop R (2011) Oxytocin selectively gates fear responses through distinct outputs from the central amygdala. Science 333(6038): 104-107

Wang JW, Lundeberg T, Yu LC (2003) Antinociceptive role of oxytocin in the nucleus raphe magnus of rats, an involvement of mu-opioid receptor. Regul Pept 115(3):153-159

Wang L, Martinez V, Larauche M, Tache Y (2009) Proximal colon distension induces Fos expression in oxytocin-, vasopressin-, CRF- and catecholamines-containing neurons in rat brain. Brain Res 1247:79-91

Wierda M, Goudsmit E, Van der Woude PF, Purba JS, Hofman MA, Bogte H, Swaab DF (1991) Oxytocin cell number in the human paraventricular nucleus remains constant with aging and in Alzheimer's disease. Neurobiol Aging 12(5):511-516

Williams AC, Craig KD (2016) Updating the definition of pain. Pain 157(11):2420-2423

Yang J (1994) Intrathecal administration of oxytocin induces analgesia in low back pain involving the endogenous opiate peptide system. Spine (Phila Pa 1976) 19(8):867-871

Yang J, Yang Y, Chen JM, Liu WY, Wang CH, Lin BC (2007) Central oxytocin enhances antinociception in the rat. Peptides 28(5):1113-1119

Yang J, Li P, Liang JY, Pan YJ, Yan XQ, Yan FL, Hao F, Zhang XY, Zhang J, Qiu PY, Wang DX (2011a) Oxytocin in the periaqueductal grey regulates nociception in the rat. Regul Pept 169(1-3):39-42

Yang J, Liang JY, Li P, Pan YJ, Qiu PY, Zhang J, Hao F, Wang DX (2011b) Oxytocin in the periaqueductal gray participates in pain modulation in the rat by influencing endogenous opiate peptides. Peptides 32(6):1255-1261

Yoshida M, Takayanagi Y, Inoue K, Kimura T, Young LJ, Onaka T, Nishimori K (2009) Evidence that oxytocin exerts anxiolytic effects via oxytocin receptor expressed in serotonergic neurons in mice. J Neurosci 29(7):2259-2271

Yu SQ, Lundeberg T, Yu LC (2003) Involvement of oxytocin in spinal antinociception in rats with inflammation. Brain Res 983(1-2):13-22 